\title{
OS LIMITES DO LIMITE
}

TROPICALISTA LENTA LENTA. TOM ZÉ. [SÃO PAULO:

PUBLIFOLHA, 2003, 288 P.]

Tropicalista lenta luta, de Tom Zé, é uma revisão importante da história da canção brasileira recente. É composto de uma autobiografia singular, textos de sua autoria sobre diversos assuntos, uma entrevista de fôlego, transcrição das letras de suas canções, discografia e curriculum vitae. Todas essas partes formam um painel amplo sobre Tom Zé e sua obra musical, de leitura indispensável não só para todos que se interessam pelo cantor e compositor, mas também para quem tem algum interesse na música popular e seus desdobramentos na cultura.

O livro abre com uma autobiografia fragmentada e reflexiva. É a parte que dá título ao livro: sua lenta luta. Trata-se de uma exposição da gênese biográfica do seu modo pessoal de fazer arte, uma descrição detalhada desse fazer e uma definição dos limites entre este fazer, o Tropicalismo e o tempo que os engendrou (tudo isso numa prosa entrecortada e polifônica, bem ao gosto da poética do autor).

Grosso modo, Tom Zé diz que seu modo de fazer canção é marcado pela idéia da espontaneidade. Nas suas palavras: "Essa era uma grande preocupação minha lá no começo, em Irará: fazer parecer que tudo na cantiga acontecia natural, no correr do tempo, como o dia, como a vida, quase improvisado" (p.32). Mas essa coin- 
cidência entre o tempo da vida e o tempo da canção era pura encenação: "Desenvolvia técnicas, estudava expressões faciais, programava cada vez que levantaria ou abaixaria a cabeça, estudava o momento conveniente para abrir e fechar os olhos, praticando durante horas no espelho - tudo casual" (idem). É o que seu parceiro José Miguel Wisnik chamou de "espontaneidade inequivocadamente construída" e que o relato vem agora desenvolver ${ }^{1}$.

Só que Tom Zé não apenas descreve seu modo de apresentação "casual" da canção, mas também detalha como essa "casualidade" pode plasmar-se na própria letra da música. Quando ainda era jovem em Irará já pensava em rever a canção tradicional pelo diapasão da espontaneidade. Para tanto, propunha quatro mudanças: 1) trocar o tempo do verbo do pretérito para o presente do indicativo; 2) falar do espaço onde vivia e não de lugares remotos; 3 ) achar um novo acordo tácito entre o cantor e o ouvinte por meio de um assunto que os identificasse; 4 ) tirar tudo que impedisse a eficácia da representação (p. 21-3). O momento deflagrador desta revisão da canção tradicional teria sido o fato de que certa vez não conseguiu cantar para sua namorada na juventude: ao descobrir-se insuficiente como cantor, resolveu transformar-se nu- ma espécie de des-cantor e compor des-canções. Em outras palavras: transformou sua insuficiência em sedução, ao encenar a ausência de encenação, e fez da experiência da imperfeição um modo de deslocar o limite do limite (a paródia tantas vezes apontada em sua obra é apenas uma das manifestações dessa experiência fundamental).

Luiz Tatit, que participou com Arthur Nestrovski da entrevista deste volume, fez uma exegese interessante da obra de Tom Zé baseado nesta idéia de insuficiência. Diz ele durante a conversa: "Você [Tom Zé] começou a produzir nesse intervalo mesmo das coisas que não chegam lá [...]. Uma imperfeição o tempo inteiro. A idéia do perfeito é a coisa acabada; o imperfeito é a coisa pela metade, que está chegando lá” (p. 223-4). E completa: "O imperfeito é nosso cotidiano. Já as obras de arte, quando se consegue chegar a um produto interessante, a gente considera aquilo perfeito [...]. Mas você parece que está extraindo sua estética de algo que é imperfeito, algo que é tipicamente cotidiano" (p. 224). A observação do compositor e professor paulista é fundamental sobretudo se pensarmos como a trajetória de Tom Zé acabou por transformar a deficiência inequivocadamente construída em princípio de organização de seu fazer artístico (declaradamente a partir do dis- 
co Com defeito de fabricação, mas sempre presente). $\mathrm{O}$ que teve conseqüências na recepção de sua obra: nem sempre entendida entre a década de 70 e 80 , mas muito bem aceita depois que se tornou referência para as vanguardas nova-iorquinas dos anos 90. A insuficiência bem talhada de Tom Zé precisou do selo estrangeiro para que se entendesse por aqui como ela fundamentava sua criação: é graças ao reconhecimento fora do Brasil que se viu a obra do cantor e compositor numa perspectiva mais ampla, e não somente sob o guardachuva do Tropicalismo. É o próprio Luiz Tatit quem completa esta interpretação: "o Tropicalismo e você tinham interesse em música nova, tinham pontos em comum. Tinham tido informação de vanguarda e tudo isso. Mas não tinham os mesmos propósitos, os projetos eram diferentes" (idem).

De fato, o Tropicalismo forçou o limite do limite para dar conta de uma insuficiência no plano da expressão para representar o salto qualitativo do processo cultural dos anos 60 (ligado à urbanização acelerada, ao desenvolvimento da indústria cultural, ao acirramento das tensões políticas e a toda uma série de fatores, cuja enumeração não cabe aqui, que tornaram essa década um ponto de inflexão em nossa história). Uma de suas táticas prediletas foi embaralhar dualidades, tais como: nacional e estrangeiro, alto e baixo, vanguarda e kitsch, arcaico e moderno, crítica e integração, e muito mais, para criar um novo acordo tácito entre cantor e ouvinte (como se vê, até aqui tudo se parece com as estratégias do compositor de Irará). Só que as características desse novo contrato, que resultou na canção pop dos anos 70, eram muito diferentes das que almejava a poética da insuficiência de Tom Zé, e o que foi fator de conjunção no momento heróico do movimento resultou em disjunção na década seguinte.

A poética da insuficiência, contudo, não esgota a parte mais estritamente musical do processo de composição (embora também o explique). Numa passagem preciosa, Tom Zé detalha um procedimento importante em sua criação dos anos $70 \mathrm{em}$ diante, quando suas canções simultaneamente conservam e modificam as feições iniciais de crônica musical e de embaralhamento legível somente sob a ótica tropicalista: "Foi assim: eu tinha uma bateria de samba, em ritmo meio lento e mais rápido. E sentava para compor: botava a bateria de samba, pegava a quinta e a sexta cordas do violão e tentava uma pequena frase, um ostinato [motivo de base, que se repete sempre]. Quando ficava gostoso - depois eu percebia - é porque mo- 
dificava ligeiramente a batida de samba. Dava alguma coisa diferente; um molho tão gostoso que eu não podia mais abandonar. Tento fazer assim com os cavaquinhos, um contraponto muito rígido, no sentido estrito" (p. 215, grifo meu). O que se revela é precioso porque o compositor oferece de bandeja um dos mais significativos princípios estruturantes de sua composição musical, ao mesmo tempo que indica certo dispositivo importante no arranjo do Tropicalista lenta luta.

A Fonte da Nação, a cultura oral nordestina, a poesia popular, a modernização de Irará, as namoradas, a Escola de Música da Bahia: esses são alguns exemplos de motivos que se repetem como ostinato desde a autobiografia inicial, passando pelos textos recolhidos até a entrevista final (para não falar das canções: figurações e configuradoras disso tudo). O que não significa que Tom Zé fica contando a mesma história várias vezes: para quem tem apreço pela insuficiência, cada fragmento é um modo novo de dar conta da totalidade. O compositor baiano rodeia seu objeto várias vezes sem intenção de dar-lhe uma configuração definitiva, como se quisesse preservá-lo de definições que o esgotassem (a incompletude novamente é um corretivo do olhar). É nesse ponto que seus sucessivos relatos tateantes se diferenciam da autobiografia de Caetano Veloso.

No livro Verdade tropical, Caetano faz uma exposição sóbria dos tempos de sua formação e do Tropicalismo, com estrutura romanesca e análise desencantada de temas que, oriundos de um contexto marcado pela contracultura, tornaram-se pedras-de-toque dos estudos culturais posteriores (como sexualidade, identidade, miscigenação e outros objetos nos quais a análise do cantor e compositor tem interesse). Tudo isso forma um quadro largo da política e da cultura da segunda metade do século $\mathrm{xx}$, com vistas a se inserir numa tradição de interpretações do Brasil. Do ponto de vista formal, uma das estratégias de persuasão para que se dê conta com sucesso dessa ampla visada é, além da estrutura próxima a de um romance realista, a tentativa de criar um lugar para sua enunciação que parece fora das poéticas anteriores do autor (como se olhasse a si mesmo em terceira pessoa). $O$ resultado é um ponto de vista e um estilo que aparenta ser muito mais próximo do analista do período do que da subjetividade criadora: uma armação cênica nada desprezível, cujo misto de matéria vivida e objetividade dá fôlego a seu modo particular de ver a verdade, e facilita o câmbio sutil entre existência pessoal e históri- 
ca (cujo potencial interpretativo ainda está para ser avaliado).

A autobiografia do início do Tropicalista lenta luta é quase o oposto simétrico de Verdade tropical: em vez da busca da forma objetiva, a subjetividade explicitamente construída; no lugar da análise desencantada das pedras-de-toque da contracultura, a visada apaixonada sobre temas variados de muitas formas de cultura (de vários tempos e espaços, como veremos); ao invés da interpretação sóbria do Brasil, a consciência da condição periférica numa prosa nos limites de sua desintegração (e que põe em evidência o horizonte convulso no qual se desenha a relação entre sujeito e mundo). Se a verdade de Caetano é uma totalidade fechada, a partir de um ponto de vista que dá limites quando quer, a de Tom Zé é um círculo incompleto, que tem certo prazer em desfazer limites (coerente com sua espontaneidade construída, como vimos).

Mas nem tudo é incompletude em Tom Zé. Nas várias passagens em que fala de sua infância em Irará parece que ele nos franqueia a passagem para um mundo preservado da insuficiência (mesmo que o apresente sob a ótica da incompletude). Um exemplo tirado da entrevista: "Vou lhe contar: quem nasce no sertão não pode dizer que não estudou poesia [...]. Quem nasce no sertão está ligado à Provença do século 12 - que não é mole, Arnault Daniel, aquele que Dante chamou de il miglior fabbro" (p. 263). E ainda: "Uma coisa recorrente lá é a da poesia concreta, com que o povo convive" (idem). Ou seja, o sertão é o mundo: desde a poesia provençal até a poesia concreta, tudo cabe neste completo sertão da cultura oral nordestina. Pena que toda transcrição de uma entrevista de Tom Zé não dê conta de como ele, nesses momentos de rememoração do tempo perdido, concentra uma tal intensidade no rosto, no gesto, na respiração, na voz, na inflexão e muito mais, que parece instaurar um deslocamento espaçotemporal.

De fato, Tom Zé dá a impressão de ter atravessado todos os tempos e espaços: do sertão que lembra a Idade Média às cidades cujo único presente é o fascínio pelo futuro. No entanto, isso não significa que o compositor queira se situar fora da história: há um engajamento em toda sua vida e obra que é um sinal inequívoco do compromisso com seu tempo. No livro é possível ler sua posição política nas letras das músicas (desde "Parque industrial" até a recente "Companheiro Bush"), em textos (há até uma carta ao presidente Lula nos escritos recolhidos), na autobiografia (sua passagem pelo CPC da UNE, por exemplo) e na entrevista. Durante es- 
ta, o engajamento ganha um relevo singular, sobretudo nas histórias em que Tom Zé descreve seus primeiros contatos com a tecnologia.

O espanto com o desencantamento do mundo propiciado pela modernização de Irará não aparece como exotismo, mas ao contrário: suspende por um momento as características do mundo urbano em que vivemos e inscreve-o violentamente na história. O leitor habituado com a luz elétrica, com a água encanada e outras particularidades da cidade grande, de certo irá se surpreender com a descrição da chegada destas ao sertão, sobretudo quando notar que elas não implicam somente ganhos, mas sempre uma relação ambígua. Assim, se por um lado a experiência estética que Tom Zé tem como matricial, a Fonte da Nação, perde solo no mundo da água encanada, por outro é sua perda que faz possível o maravilhamento diante da luz elétrica. Daí a ambigüidade: não há elogio regressivo da cultura pré-industrial (como faria supor um sertão-mundo tomado ingenuamente), como também não há o fascínio sem mais pela tecnologia (o sertāo-mundo é uma espécie de amuleto que permite ver melhor os fantasmas do progresso).

A poética da insuficiência quando pensada em sua relação com a tecnologia é profundamente política: ela garante uma certa independência em relação ao aparelho tecnológico e econômico cujo interesse não é pequeno. Primeiro, porque desmascara o fetiche da tecnologia, seja ao valer-se de modos de composição e gravação que tentam driblar os programas estéticos já embutidos em toda máquina ("a máquina é um censor estético do sistema”, como ele diz na p. 218), seja ao tematizar esse fetiche (por exemplo, na letra de "Ogodô ano 2000", que traz tiros precisos como: "A ciência excitada/ Fará o sinal da cruz/E acenderemos fogueiras / Para apreciar a lâmpada elétrica"). Se este ponto já diz muito sobre as miragens do progresso, é o seu desdobramento mais rente à economia que nos mostra nitidamente o alcance de sua função crítica.

A incompletude programada problematiza nossa condição periférica ao internalizar nosso subdesenvolvimento em sua forma (nesse plano seria interessante rever como a poética da insuficiência tem paralelo com a estética da fome de Glauber Rocha). No disco Com defeito de fabricação, por exemplo, Tom Zé usa de toda sorte de "lixo civilizado" (brinquedos, carros, serras e muito mais) para desconstruir um vasto repertório do que se entende por música (de Korsakov a Martinho da Vila) sob o diapasão da insuficiência e repô-lo sob a estampa ambivalente do defeituoso e do fora dos li- 
mites. Assim, compôs canções que introjetam nosso subdesenvolvimento (pela insuficiência), tomando o cuidado para não apresentá-lo como algo exótico (pois repertório do centro e da periferia se nivelam), e revelando assim, pela forma, o aspecto profundo de nossos "defeitos" (nossa situação inaceitável é parte fundamental da ordem mundial). Tudo isso fica ainda mais claro ao se levar em conta o aspecto iconoclasta do compositor: quando fizemos o videoclipe da canção "Defeito 3: politicar”, por exemplo, Tom Zé criou algumas cenas em que queimava e rasgava dólares, dando a ver com extraordinário grau de síntese a disposição crítica de seu deslocamento de limites (no caso, ao pôr em questão o valor sagrado da forma mercadoria e do capital universal simbolizado no dólar). A encenação provocadora geralmente causava reações reveladoras do fetichismo em que todos estamos metidos (o que é sempre um lembrete de como a quebra de limites pode às vezes funcionar como dispositivo que corrige o olhar para o que é essencial).

Como se vê até aqui, a feição crítica da obra de Tom Zé é ampla e isso já é prova mais que suficiente para mostrar como o alcance do livro Tropicalista lenta luta ultrapassa o interesse meramente informativo-musical. Trata-se de mais um testemunho da capacidade insti- gante que o cantor e compositor tem para pensar nossa condição.

1 WISNIK, José Miguel."Te Manduco-Não Manduca". Folha de S.Paulo, São Paulo, 29.7.2001. Mais!, p.17.

Daniel Sampaio Augusto é diretor de cinema e televisāo. Criou, dirigiu e editou a série de documentários "Mapas Urbanos."É mestrando em Literatura Brasileira na Universidade de São Paulo. 